\title{
INTERACTIVE COMMUNICATION STRATEGIES AS TOOLS FOR UNDERSTANDING THE ART WORLD IN THE POST-LITERACY ERA
}

\author{
Elena Rubtsova \\ PhD., Associate Prof. Ural Federal University, RUSSIA, rbtsvelena@rambler.ru
}

\begin{abstract}
The paper argues the ways in which artwork representation to its agents (artists, critics, curators, and audience) in the new sociocultural post-literacy situation revises traditional art communicative systems. Relying on an understanding of art as a public communication, the new "art communication" or "communication in the art world" concept is presented in the forms of manifestos and special types of comments from the perspective of modern aesthetics. However, this characteristic does not represent an attempt to understand the traditional artist's set sense in his communication, or at least this is not the agents' first question, but a way of asking how, for example, ready-made or performances have become art. The problem the paper explores are the opportunities art gives for interaction and/or resistance in the global social sphere that give participants a new type of literacy (even we can speak about post-literacy). In other words, contemporary practice in modern art propounds the impossibility to speak of a concise, exhaustive standard definition that will help agents grant art status to new objects. As a result, it can be concluded that the artist's new communicative strategies are many, not only one as in the past, and at the same time, they do not follow one another. This implies that to understand the strategies we should think in terms of a new post-literacy situation where there is not only one "alphabet". The paper concludes that the problem of Aesthetics as a science is not an expansion of its borders as seen and thought in art practice during the XX century.
\end{abstract}

Keywords: Art world, artwork, communication strategy, art agents.

\section{INTRODUCTION}

From the social sciences point of view, communication is the human activity that unites society. It consists of three aspects: the sender, the addressee and the medium of communication. To this basic communication model, other variables having a stake on the process such as noises or interferences, incorrect processing and retrieval of information, contextual features, competencies, and human emotional states have been added. Consequently, art philosophy identifies the sender with the artist; the addressee, with the other agents of the art world; and the medium of communication with the art object. In other words, communication in the art world is object-mediated. The advent of Modern Art brought with it interferences in what could be 
considered art, misinterpretations, and very many rejections to art objects for they did not consistently fit into the existing theories. Addressees could not understand why, say, objects derived from futurism, Dada, installations, or performances had made it to museums, art galleries and expositions when compared with the beauty and harmony of a Da Vinci, a Botticelli or a Raphael. In other words, the long established communication system between the artist as sender and the receivers as addresses had been broken; a phenomenon that, unfortunately, is still present today.

The problem the paper explores are the opportunities art gives for interaction and/or resistance in the global social sphere that give participants a new type of literacy (even we can speak about post-literacy). I will argue that contemporary practice in modern art propounds the impossibility to speak of a concise, exhaustive standard definition that will help agents grant art status to new objects.

\section{DEVELOPMENT}

Understanding something as art requires some type of evaluation. Robillard (2005, p. 224) warns that "Sometimes it is likely possible for someone to evaluate some kind of social behaviour, from directly observing the fact, action or event being realized before one's eye." To which he adds (ibid), "What one can observe, then, is in fact the bond that ties the observable fact, action or event and the intentionality of the actors, which we can both infer inductively from our comparing what is being observed and our actual social common knowledge." Therefore, it follows that the lack of social knowledge necessary to arrive at accurate inductive inferences is the aspect affecting the new kind of understanding needed to comprehend what is meant by art today. In other words, cognition mediates understanding of art and non-art. Therefore, new ways of expression not aligned to traditional paradigms may be appreciated as non-art when they are really just new ways of art-making.

Resistance to changes in established paradigms is not something new in the history of humanity. For instance, Giordano Bruno's rejection of geocentricity led him to death at the stake. When Einstein questioned Newtonian mechanics, his theory was met with skepticism, and no one believed him. Had the horrible 'purifying' execution by fire existed as in the Middle Ages, the famous physicist might probably have ended as the Italian Dominican friar. This same pattern has been present in the world of art. The issue is that new ideas are hardly accepted at first. In the art world, the artist's subjectivity expressed through objects as representatives of an objective world is (mis)understood due to the agents' own subjectivity. The problem is not the object itself, but generated by the involved conflicting subjectivities.

Modern art has developed in a new world that is quite different from the past. The revolutions in science, technology as well as the appalling disruption of the normal course of life as a result of wars, famine, poverty, diseases and the like have brought with them new forms of art expression that in no way resemble the more or less stable past. Therefore, a hostile world cannot give birth to beauty. In other words, as Holmogorova (2002, p. 348) puts it, "during an era of more and more lost realities, is it important if the king is naked?" But the curator, the great mediator of action, the one who chooses if the object is introduced to the public can easily convince people that the king is dressed, that in his nakedness he is dressed. "Or is it not?" (Ibid; my bold). I contend that by comparing what curators are supposed to do with Andersen's short tale Holmogorova attacks the curator's vanity and pride in not honestly recognizing the value of thousands of modern art forms. In other words, they are still living in the beauty of the past and cannot see the present.

On the other hand, art critics, the know-it-all who may, if wanted, decide if something is art or not follow the same path. The function of the art critic - perhaps art commentator would be a better way of putting it- for they are hardly able to produce art- consists, it is thought, in preparing such (un)protective text-clothes for works of art. These texts are not exempt of criticism either for they are "from the start, texts not necessarily written to be read" (Groys, 1997, p. 111; my italics).

The two quotes above use the same metaphors for the designation of various strategies and figures. In the end, who is producing art? The curator? The critic? This article explores the ways in which questions such as who or what in the modern art world is "the naked king": art, work of art, or art institutions? Is it possible to process the "exposure" and "clothing" of art? Who, finally yet importantly, should engage in this process? Is it the artist, the critic, the curator, or the viewer, or all together? The writers believes that today these questions are decisive for the production and perception of art objects.

Understanding art as a form of public communication is a settled practice in Art Studies today. The reference point in the analysis of any modern art situation can be found in N. Bourrias's assertion, "Each particular artwork is a proposal to live in a shared world, and the work of every artist is a bundle of relations with the world, giving rise to other relations, and so on and so forth, ad infinitum (2002, p. 22)." In other words, art acts as some kind of attempt to address the Other. It acts under a desire, a power, or an unconscious idea. 
In addition, not only does the artist undertake the function of a mediator, but also others coming from all the other figures of the world of art by becoming an active figure in the communication processes. 'Communications', a conceptual category in modern art, reflects the art world agents' interactions in totally different ways, ways that are still alien, unfortunately, to many art connoisseurs. In the new sociocultural situation of post-literacy, Gudova M. (2013) warns that mastering the alphabet is not enough to read for the same object looks different from different points of view and this gives rise to different interpretations. Today, an art object is sometimes a multimedia hypertext (regardless of its network or non-network nature), where the artist assumes the functions of author, commentator, editor and publisher; that is, the artist himself becomes the person who constructs and reviews the art object/text. He is his own curator and art critic.

For the act of communication to take place, modern art needs the 'comment'; otherwise, comprehension processes would be unclear or limited. The comment or manifesto becomes the clothes that dress the new art object; however, these texts are of a special type. That is, if traditional art needs a comment that explains what the picture of an old master is about; in the case of the modern art, the text or comment is the attempt to answer another question: why a given object, ready-made, or performance is art. That is, the note is not intended to help the addressees or agents understand, rather it is a decision made by the world of art where the artist has the leading voice in creating the harmony his melodic lines are intended to create.

It should be noted that art as a form of communication manifests itself as a special sphere of public activity. As such, artists address the agents by means of an already developed and accepted system of social communications and join this world by using such long established forms of interaction. However, in the particular case of modern art, it is possible to speak about a plurality of artistic practices and understandings ever since art appears as group of interconnected cultural actions that include its perception. This means that each practice comes under the influence of the world around, and each has to change and develop to adapt to the new circumstances. Since many art practices are possible, it follows that the ways of object identification as artistic are just subjective interpretations without definite and accurately fixed rules.

In the art world, many are vehemently opposed to dominating theories. Consequently, it is very unlikely that the near future will witness the birth of a uniform definition that could help allocate art status to new objects. Until that moment arrives, the American researcher N. Carroll has designated these identification strategies as copying, expansion or denial of artworks all of which are recognized as traditional. On the other, as identification strategies within cultural practices are not rigid definitions of art, their explanation through a narrative has become necessary. That is, in their dialectical relationship, "New works can inform our understanding of past art, while past art informs our understanding of new art. This understanding proceeds by historical narration, which is both forwards- and backwards- looking, and which discloses lines of development through such recurring patterns as repetition, amplification, and repudiation" (Carroll, 2003, p. 72-73)."

Therefore, I consider that when an existing direction changes, agents have to correct, or rather redefine, what is understood by art. The importance of the narrative aspect consists in that new objects are defined as art through art stories, rather than theories. That is, from the external point of view, the theories on art that protect the work and substantiate it as belonging to, say, realism, surrealism, conceptualism are impossible to be applied to modern art; at the same time, nor can the artist's suppositions, seen as the internal aspect of the artwork, be used as a validation concept.

\section{CONCLUSIONS}

In the era after avant-garde, the main thing for the world of art is not an expansion of its borders (because sometimes artists tell us that art is life and life is art), but research on art interaction opportunities (or art resistance) in the global social sphere. Therefore, the problems of communication with and inside art world depend on pluralistic point of views, regardless of the fact that a universal point of view is, at least at the moment, impossible to reach. Now one cannot speak about the objective and unchanging properties of artistic objects, just in the same way one cannot talk in one art language providing the means for art description. On the contrary, there are many and they depends on using communication strategies.

The artist's new communicative strategies are many, not only one as in the past, and at the same time, they do not follow one another. This implies that to understand the strategies we should think in terms of a new post-literacy situation where there is not only one "alphabet". The problem of Aesthetics as a science is not an expansion of its borders as seen and thought in art practice during the XX century. 


\section{REFERENCE LIST}

Bourrias, N. (2002). Relational aesthetics. Les press du reel.

Carroll, N. (2003). Beyond Aesthetics: Phylosophical Essays. Cambrige University Press.

Groys, B. (2008). Art power. Critical Reflections. The MIT Press.

Gudova, M. (2013). Multiple Forms of Art Dialog in the Modern Reading. In: $19^{\text {th }}$ International Congress of Aesthetics. Aesthetics in action. Krakow, Poland. Book of abstracts. Pp.115.

Holmogorova, O.V. (2002). Kuratorskie strategii 1990-ih. Hudozhestvennaya kultura 20 veka: razvitie plasticheskih iskusstv: sb. st. - M.: Rus. Slovo, 2002. - S. 335-351.

Robillard, J. (2005). Philosophy of Communication: What Does It Have to Do With Philosophy of Social Sciences. Cosmos and History: The Journal of Natural and Social Philosophy, vol. 1, no. 2. 2005. Pp. 245-260. 